\title{
Chondrogenic Neoplasm
}

National Cancer Institute

\section{Source}

National Cancer Institute. Chondrogenic Neoplasm. NCI Thesaurus. Code C4755.

A benign, intermediate, or malignant cartilaginous matrix-producing neoplasm.

Representative examples include osteochondroma, chondroblastoma, and chondrosarcoma. 